\title{
The effect of organisational context on organisational development (OD) interventions
}

\begin{abstract}
Author:
Sanjana Brijball Parumasur ${ }^{1}$

Affiliation:

${ }^{1}$ Discipline of Human

Resource Management,

School of Management, IT

and Governance, University

of KwaZulu-Natal, South

Africa

Correspondence to:

Sanjana Brijball Parumasur

Email:

Brijballs@ukzn.ac.za

Postal address:

Private Bag X54001, Durban

4000 , South Africa

Dates:

Received: 2008

Accepted: April 2010

Published: 16 May 2012

How to cite this article: Brijball Parumasur, S. (2012) The effect of organisational context on organisational development (OD) interventions. SA Journal of Industrial Psychology/SA Tydskrif vir Bedryfsielkunde, 38(1), Art. \#1017, 12 pages. http://dx.doi.org/10.4102/ sajip.v38i1.1017
\end{abstract}

(C) 2012. The Authors. Licensee: AOSIS OpenJournals. This work is licensed under the Creative Commons Attribution License.
Orientation: Systematic and congruent organisational structures, systems, strategies and designs are necessary for the successful implementation of organisational development (OD) interventions.

Research purpose: This article examines national and international OD practices. It assesses the effect of diverse cultures and cultural values for determining the effectiveness of OD interventions.

Motivation for the study: Most organisational change and development programmes fail and only a few result in increased competitiveness, improvements and profitability. This emphasises the need for change interventions to give sufficient attention to leadership, cultures, managing change and adopting context-based OD interventions.

Research design, approach and method: This article is a literature review of the current trends and research in the area of OD interventions. It synthesises the influence that cultures and cultural orientations have on determining which OD intervention strategies organisations should adopt in different cultures.

Main findings: The analysis emphasises how important it is to achieve congruence between the OD interventions organisations select and their local cultures.

Practical/managerial implications: It is important to note the evolving nature of the political and economic climates that influence national cultures and that they emphasise that interventions that reflect OD values, which are tailor-made and shaped to the needs of local cultures, are necessary.

Contribution/value-add: This study links various OD interventions to Hofstede's dimensions for differentiating national cultures. It provides guidelines for aligning the practices and techniques of OD to the values and cultures of the organisations and societies in which they are to be implemented.

\section{Introduction}

\section{History of organisational development}

In the last 40 years, OD has progressed from a limited conceptual and practice base into a comprehensive, global approach to organisational improvement (Glassman \& Cummings, 1991). One can ascribe its introduction, methodologies and subsequent international burgeoning to several factors:

- the increase in the number of businesses that reach global markets (Lau, McMahan \& Woodman, 2005; Peterson, 1997)

- the rapid growth and transformation of organisations have demanded the use of OD interventions to manage changes (Pettigrew, Woodman \& Cameron, 2001)

- the increasing number, size and sophistication of industrialising economies (Golembiewski \& Luo, 1994)

- technological advancements and knowledge management have enabled organisations to engage in planned change (Cummings \& Worley, 2001).

According to Blair, Sorensen and Yaeger (2002), OD interventions play important roles in dealing with a dramatically changing world that turbulence and trauma characterise. American and Western European consultants developed OD. Therefore, the values and assumptions of western, industrialised cultures influence its practices and techniques. However, they might conflict with the values and assumptions of other societies. Therefore, the applicability and effectiveness of OD outside the United States of America (USA) and the relationship of theory and practice to different cultures are major concerns to academics and practitioners.

However, some practitioners believe that OD can still result in developments, organisational improvements, growth and renewal in any culture. The success of OD interventions in 
organisations will depend on the extent to which the values and assumptions of the organisations and countries match those of the USA. Furthermore, the level of economic development in the countries will also influence the success of OD interventions.

\section{Purpose of the study}

This article aims to examine national and international OD practice. Secondly, it aims to assess the effect of diverse cultures and cultural values on the use and effectiveness of OD interventions. The emphasis of the article is on the necessity to achieve congruence between the OD interventions organisations select and on the cultures of the organisations and societies where these techniques are to be implemented.

\section{What will follow}

The structure of the article follows. It first explores the link between organisational elements and changing organisational contexts. It then reviews three proposed typologies to characterise organisational cultures. Thereafter, the article discusses a contextualised and customised approach to planning and implementing OD interventions. A discussion about the contextual differences between developed and emerging economies and their effect on OD interventions follows. The article then evaluates contextual differences in national cultures and management practices and their effects on OD interventions. The article concludes with an assessment of critical success factors for OD practitioners or consultants who work in multicultural contexts.

\section{Linking organisational elements, particularly organisational cultures as a focus of change, to changing organisational contexts}

Various pressures and forces of change, like shifts in organisational structures; rapidly changing markets; technological advances; the focus on core abilities to achieve excellence, growth and customer-orientation; globalisation; outsourcing; and networking have affected organisations during the last decade (Howard, 2006; Nilakant \& Ramnarayan, 2006). When organisations' current cultures do not align with their current business strategies, they need culture change interventions. However, changing cultures is a difficult and time-consuming process and demands interventions at all levels.

British and American literature shows that most organisation change and development programmes fail. Most downsizing, delayering and total quality management (TQM) initiatives are unsuccessful and few result in increased competitiveness, improvements and profitability (Hamlin, Campbell, Reidy \& Stewart, 1999). Research shows that numerous change interventions fail because managers do not give sufficient attention to leadership, culture and managing change (Bennis, 2002; Boonstra \& Vink, 1996; Brooks \& Bate, 1994; Hamlin, 2005; Hamlin et al., 1999; Hamlin, Keep \& Ash, 2001; Kotter, 1996; Ogbonna \& Harris, 2002; Warrick, 1995).
The situation is even bleaker with regard to culture change, where the failure rate exceeds $80 \%$ in the United Kingdom (IRS, 1997).

When these organisation culture change initiatives fail, they seriously damage organisations and have unintended psychological consequences for the people in them. They have a spiralling effect because they affect employees psychologically and demoralise them. Employees respond by engaging in adverse behaviour that affects business. Staff turnover, training and retraining costs increase. Organisations lose key employees, have to use contract workers and have to outsource important functions. As organisations change, so do their cultures. This influences the type of OD interventions they could adopt. Therefore, OD interventions must be compatible with their structures, systems, strategies and designs and must align with organisational cultures.

One can view organisations' cultures as the invisible webs their members spin over a period. They net values and expectations, and knit groups of people. According to Johnson (1988), a cultural web is the interplay of organisations' paradigms, control systems, structures, power structures, symbols, rituals and routines, stories and myths. Organisational contexts play critical roles in OD and OD interventions. Several typologies characterise organisational cultures. This article discusses three typologies: those of Deal and Kennedy, Handy and Schein.

\section{The typology of Deal and Kennedy}

Deal and Kennedy (1982) defined organisational cultures as how organisations get things done. They differentiate organisations according to feedback (quick feedback implies an immediate response) and risks (the extent of uncertainty in their functions). Deal and Kennedy used these differentiators to distinguish between four classifications of organisational cultures:

- the 'tough-guy macho' culture, which quick feedback, high rewards and stress characterises

- the 'work hard, play hard' culture, which few risks and rapid feedback characterises

- the 'bet your company' culture, which taking big stake decisions (and the passage of several years before any results materialise) characterises

- the 'process' culture, with little (if any) feedback and few bureaucratic processes but which produces consistent results.

\section{The typology of Charles Handy}

Handy (1985) linked organisational structures to organisational cultures and distinguished between four types of cultures (cited in Harrison, Wheeler \& Whitehead, 2003; Kane-Urrabazo, 2006):

- a 'power culture', where a few people, who control the system with few rules and little bureaucracy, have all the power and make decisions effectively

- a 'role culture', where people have clearly-delegated 
authority within a clearly-defined structure; it has hierarchical bureaucracies and people's positions determine their power

- a 'task culture', where teams form to solve problems and manage projects or tasks; it thrives on expert power

- a 'person culture', where people believe that they are superior to the organisation; people work and exist entirely for themselves.

\section{The typology of Edgar Schein}

Schein (1985) believes that organisational cultures are the most difficult organisational attributes to change. He developed an organisational model that comprises three cognitive levels of organisational cultures (cited in Wikipedia, OC, 2006):

- The first and most cursory level comprises organisational attributes (e.g. facilities, offices, visible awards and recognition, furniture, dress, interpersonal and intrapersonal employee interaction) that outsiders can see, feel and hear.

- The second level depicts the cultures (like company logos or trademarks, mission statements and value systems) of the members of the organisations.

- The third and deepest level comprises the organisations' unspoken, unseen and unconscious assumptions; they may relate to the nature of employee interaction and may depict elements of the cultures that are taboo to discuss.

Even employees with sufficient organisational experience to understand the deepest level of culture usually become accustomed to these attributes over time, thereby perpetuating their invisibility. However, culture at this level is the underlying and driving element of any organisational culture. It reflects the context of organisations and displays paradoxical organisational behaviour patterns. For example, at the second level of Schein's (1985) model, organisations may claim moral and ethical standards. However, at the third level, members may be engaging in, or know about, fraud in the organisations.

As opposed to the functionalist and unitarist views of cultures, critical management thinkers believe that:

- No single culture exists in organisations; cultural engineering cannot reflect the interests of all stakeholders or constituencies in organisations.

- Complex organisations may have many cultures and subcultures may overlap and contradict each other; the culture typologies rarely acknowledge these organisational complexities or the various economic contradictions that exist in capitalist organisational environments (Wikipedia, OC, 2006).

- Different cultures may dominate depending on the degree of centralisation in organisations.

- Organisations are dynamic and change over time so that their cultures may change.

Organisation culture change cannot occur successfully without changing the systems, structures, technology and skills that support it. Quality leaders, who are able to manage across boundaries, are essential to building high-performing cultures. These cultures need more information, co-operation, negotiation, effective communication, innovation, creativity as well as good leadership and technological skills. Excellent interpersonal skills, gain sharing, flexibility, adaptability and continuous learning are vital to this new organisational ethos. It means breaking down organisational boundaries, creating effective partnerships, connecting computers and linking people to enable the change from old to new cultures. Therefore, the increasing pressure on organisations to change necessitates a strategic perspective of change that increases the congruency between their environments, strategies and designs. It creates many challenges for companies and OD consultants.

Organisations can manage change effectively through organisational development. OD refers to any strategy, method or technique for making organisations more effective by bringing about more constructive and planned changes (DuBrin, 1997) so that they can adapt better to new technologies, markets and challenges (Wikipedia, OD, 2006). Because OD favours changes in cultures over changes in behaviour, organisations can use various OD interventions to change their cultures, technologies or structures to bring about quality improvements and effectiveness. Figure 1 gives an overview of the discussion.

Figure 1 shows that strategic change interventions include contextualised and customised efforts to improve organisations' relationships with their environments and the match between their technical, political and cultural systems (Cummings \& Worley, 2001).

\section{A contextualised and customised approach to planning and implementing organisational development interventions}

Rather than adopting simplistic yes or no decisions to designing and applying OD interventions, OD practitioners urge that organisations need to use a curvilinear model to determine the appropriate fit of interventions to their contexts. The rationale is that too little discrepancy or gap between local values and the proposed interventions will reduce the motivation to change whilst too large a gap may discourage it (Golembiewski, 1993). Therefore, organisations should locate OD applications at the exact point where the gap begins to become discouraging but should not go beyond it.

Organisations do not accept or reject all OD interventions. However, some OD interventions may find little acceptance in particular cultures whilst the same cultures may accept others easily because of their humanistic orientations (Golembiewski, 1993; Head \& Sorensen, 1993). For example, Lau et al. (2005) found that Hong Kong firms spend more time on human process interventions and strategic planning activities but less time on technostructural and system-wide interventions. One the other hand, firms in the USA spend more time on human process and system-wide interventions. Furthermore, organisations may have to adapt some OD 


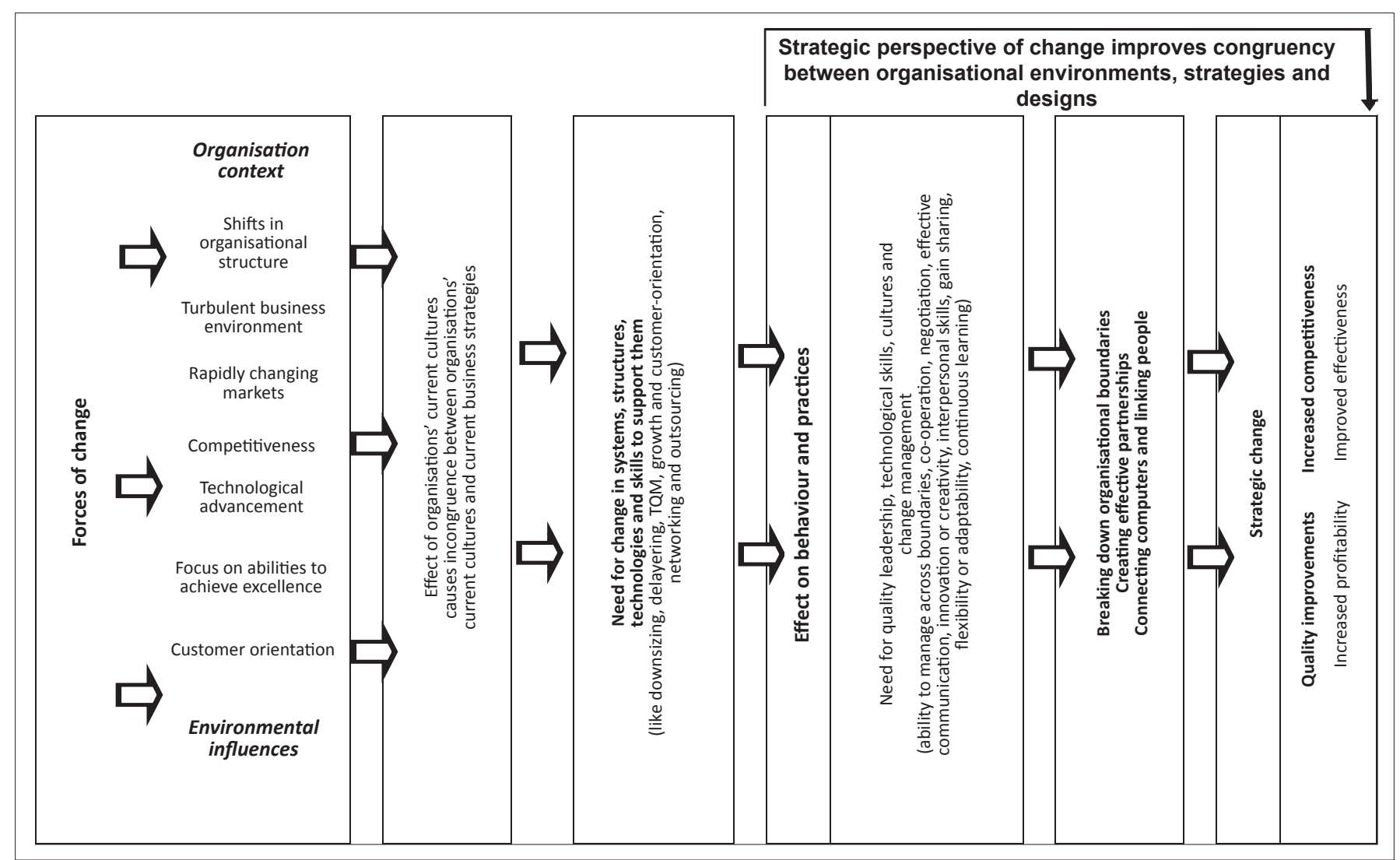

FIGURE 1: The effect of organisations' contexts on their cultures, behaviours, practices and, ultimately, effectiveness.

interventions to fit the cultural values of particular countries. OD practitioners think that they work in accordance with their values instead of prescribing their interventions (Golembiewski, 1993).

Golembiewski (1993) and Golembiewski and Luo (1994) maintain that organisations can adapt OD interventions in response to local needs. Therefore, one expects some differences in how organisations implement OD interventions in different countries with different cultural values. OD interventions always have to deal with the alignment between interventions and cultures (Golembiewski, 1993). Clearly, OD interventions are not homogenous even though they are based on a common set of values. Therefore, OD practitioners need to be more sensitive and alert to different contexts and improve their discretion about the appropriate OD interventions (Golembiewski, 1993). The implication is that:

- OD practitioners can make reasonable situational adjustments to the cultures in which they operate.

- OD technology has powerful generic features that improve adaptation to the specific experiences OD practitioners encounter in organisations in different settings (Golembiewski, 1993).

Undoubtedly, implementing OD in different organisations requires contextualised and customised approaches to planned changes. This means achieving the greatest congruence between change processes and organisations' internal cultural environments, including the employees' beliefs and values that guide them to determine which behaviours are important and acceptable in their cultures.

According to Lachman, Nedd and Hinings (1997), core values are the high priority values that are central to a social, cultural or person's value system, are important for regulating social behaviour and tend to be enduring. Several researchers (Fagenson-Eland, Ensher \& Burke, 2004; Head \& Sorensen, 1993; Kim \& Hoon, 1998; Lau \& Ngo, 2001; Lau et al., 2005) emphasise that the nature of the OD interventions that organisations adopt varies with the cultures where they operate because the values, customs and styles of interacting differ in different countries. Therefore, it is very likely that, to infer that culture-bound perspectives imply that organisations will accept or reject the designs and implementations of OD interventions (Evans, 1989; Kirkbride, Tang \& Shae, 1989) is too simplistic.

\section{Results}

\section{Contextual differences between developed and emerging economies and their effects on organisational development interventions}

The effectiveness of OD interventions depends on organisations' approaches to developing core skills or abilities, like literacy, numeracy, personal and social skills, problem solving and decision-making skills as well as information technology literacy. Many countries assume that their school systems will develop these basic skills. Therefore, it is not the function of work environments to do 
so. The United Kingdom (UK), for example, sees core abilities as a threshold standard and not as something that develops continuously (Institute of Personnel and Development, 2005).

In Japan, most people enter the workforce with a high level of abstract and symbolic thinking as well as social skills and behaviours that are in harmony with the requirements of effective teamwork. Therefore, Japanese models for developing skills and abilities strongly emphasise intellectual skills that improve the ability to manage changes and problems (Institute of Personnel and Development, 2005).

Parnell, Crandall and Menefee (2005) also found that there are several differences in the management environments in the USA and Egypt. They found that American university students reported greater levels of entrepreneurial propensity than did their Egyptian counterparts in terms of their perceived levels of entrepreneurial education, beliefs about entrepreneurial opportunities in their economies and confidence in their abilities to access available opportunities. Cultures influence each of these factors. Therefore, local contexts influence responses to culture change initiatives. Furthermore, the effectiveness of OD interventions depends on the economic development of countries.

Countries that have subsistence economies (like countries in the Middle East, Afghanistan, Bangladesh and Nigeria) favour OD interventions that focus on global social change and on creating conditions for sustainable social and economic progress (Cummings \& Worley, 2001). Industrialising economies (like those of South Africa, Brazil and China) favour OD interventions that emphasise strategic, structural and work design aspects. These interventions focus on assisting organisations to identify national and global markets, to engage in clear and suitable goal setting, to structure themselves to become efficient and effective and to increase their market share.

Industrial economies (like those of France, Japan, the USA and the UK) have advanced to post-industrial conditions. Therefore, they favour OD interventions that suit environments, which advanced technological developments, highly skilled workforces, information and knowledge management, customer-driven service delivery and open and adaptable national and organisational systems, drive. These economies, which are moving toward wealth that is more concentrated, globalisation and ecological concerns, will influence OD interventions in the future (Worley \& Feyerherm, 2003).

In many developing countries (like Kenya, Tanzania, Uganda, South Africa, Lesotho, Mozambique, Swaziland, Namibia and Botswana), the combination of lack of resources, illiteracy, the human immunodeficiency virus (HIV) and the acquired immunodeficiency syndrome (AIDS) pandemic, poor infrastructure and the inequitable distribution of their few resources hamper the potential for economic and social development. For example, the relevance and quality of basic education in Ethiopia is low. In fact, Ethiopia is amongst the African countries with the lowest educational levels - more than half of the children never have access to schools. It is also one of the most HIV and AIDS affected countries in Africa (Red Barnet, 2001).

McElroy and Morris (2002) conducted a study of African island development experiences and found that African islands (like Cape Verde, the Maldives, Madeira, Reunion and the Seychelles) show lower socio-economic development than do islands in the rest of the world. Furthermore, African islands approximate the profile of the African continent. They experience relatively low incomes, low literacy and life expectancy levels, high unemployment, high infant mortality rates, low fertility rates as well as high rates of natural disasters. Undoubtedly, cultures affect health in complex ways and, through their positive or negative influences, they affect the whole socio-economic development of African societies (Observatory of Cultural Policies in Africa and Interarts Workshop on Draft Projects Documents on the Research Priorities and Consultation on the Report on Cultural Diversity in Africa, 2006).

Cultures also have direct roles to play in providing a peoplecentred approach to development in Africa. Governments in African countries have realised that they need to encourage language pluralism and cultural diversity. They have also recognised that cultural differences and fostering democracy are fundamental to national unity and, therefore, to development (Observatory of Cultural Policies in Africa and Interarts Workshop on Draft Projects Documents on the Research Priorities and Consultation on the Report on Cultural Diversity in Africa, 2006). Dealing with developing and developed countries demands that, to be effective, OD interventions require different approaches. Each programme of work needs careful tailoring to meet the needs of particular situations.

Mutabazi and Derr (2006) maintain that multicultural team management is a complex problem, especially in Africa. Dysfunctions because of misunderstandings and difficult team relationships often occur between local African employees and western expatriate managers in Africa and highlight the dangers of multiculturalism. The technical and financial aspects of management have often overlooked cultural differences. However, they have resulted in communication and interpersonal problems between multicultural team members to the detriment of team cohesiveness and productivity. In addition, Africans think that cultures, which colonial powers and the globalised, international media have introduced, are subordinating their local cultures. This has affected their cultural lives negatively and hindered economic and social development (Response to Commission's Consultation Document, 2004).

The implication is that, whilst there are significant differences between cultures, achieving synergy in Africa and outside depends largely on the ability of managers and 
OD consultants to create management systems that 'foster complementarity and are favourable to the integration of cultural differences' (Mutabazi \& Derr, 2006). This scenario of multicultural and multinational partnerships is becoming increasingly possible as communication technologies and advancements are reducing distances and making any destination accessible because of the declining cost of air travel in real terms. This has resulted in OD practitioners facing a diverse range of cultures as locally trained consultants are beginning to practice OD across the globe because of international acquisitions.

For example, South African Pulp and Paper Industries (SAPPI) has an extensive range of international subsidiaries. Furthermore, South African Breweries (SAB) recently claimed its place in the Fortune Magazine for placing psychometrics on the map in the USA, with South African psychologists and psychometrists flying out to perform these services. In addition, sources of information are becoming increasingly available on the Internet and potential markets are becoming largely local. The implication is that OD consultants need to recognise the global effects of what they and their clients do and the effects of global developments on their clients and themselves. Therefore, cultural contexts and the economic development of countries affect how organisations implement OD interventions in them. They influence the pace of change processes, the number of members of organisations who are involved in the processes, the extent of worker participation as well as the amount of focus on strategic, organisational and human process issues.

Whilst most studies of OD interventions occurred in individual countries, the cross-cultural research, which Fagenson-Eland et al. (2004) conducted in seven countries, adds new dimensions to OD internationally, assists organisations to select the OD interventions they can use in specific countries and improves the chances of successful OD interventions. It is important to mould interventions into forms that make sense for local cultures as long as organisations recognise and nurture OD values (FagensonEland et al., 2004; Golembiewski, 1993; Head \& Sorenson, 1993). Perlaki (1994) believes that the best way to reduce the gap is to assist local people to develop their own unique theories, strategies, procedures and techniques of management in order to ensure congruence with their own unique cultures.

\section{Contextual differences in national cultures and their effects on organisational development interventions}

\section{Dimensions of national cultures that affect organisational development interventions}

Hofstede (1980) identified four unique dimensions of national cultures that affect OD interventions. These are power distance, uncertainty avoidance, individualism vs. collectivism and masculinity vs. femininity.

Power distance as a dimension for differentiating national cultures: Power distance refers to the extent to which members of societies acknowledge that organisations distribute power unequally (Hofstede, 1980). Organisations in cultures that are high in power distance tend to be highly centralised with several hierarchical levels. Nonmanagement employees come mainly from the lower socioeconomic classes (Hofstede, 1996). Consequently, these organisations accept autocratic and paternalistic decisionmaking practices (Cummings \& Worley, 2001). Very often, they move decisions up as far as they can go (Hofstede, 1980). Similarly, Russell (1997) maintains that, in high power distance societies, one naturally expects inequalities between social groups. Therefore, there tend to be large social and economic gaps between those who have power and those who do not. Subordinates in these cultures expect close supervision and believe that those who hold power are entitled to special privileges (Cummings \& Worley, 2001).

Westwood, Tang and Kirkbride (1992) examined Chinese conflict behaviour and suggested that one might see open disclosure and critical reflection as threats to authority and hierarchical relations. Therefore, Chinese-dominant communities do not accept them. In addition, one of the main tenets of the Chinese cultural system is the value of hierarchical relationships that still prevail in China (Lachman et al., 1997). The converse is true of organisations low in power distance (German-speaking countries) that tend to adopt a more participative and egalitarian decision-making approach (Fagenson-Eland et al., 2004; Harzing \& Hofstede, 1996). Russell (1997) maintains that low power distance societies attempt to reduce inequality between classes and emphasise the ideal of equal rights for all their members, even if they do not achieve it perfectly.

Specific interventions linked to the power distance dimension: In their study, Fagenson-Eland et al. (2004) found that South Africa has the highest degree of power distance compared to Finland, Ireland, the Netherlands, New Zealand, the UK and the USA. Therefore, it is the least likely to use group process activities. However, with the changes in political and social structures that occurred during the transition from apartheid to democracy, the power distance and inequality between race groups began decreasing. Thomas and Bendixen (2000) found that South Africa's power dimension index is now significantly lower than it was before. Fagenson-Eland et al. (2004) found that South African OD practitioners, following the UK, were more likely to use group process interventions than were their counterparts in Finland, the USA, Ireland, New Zealand and the Netherlands.

The evolution of the political and economic climate of countries seem to play significant roles in determining their extent of power distance and the OD intervention strategies and focus their organisations select. Furthermore, as countries become more global and operate beyond their borders, national education, products, systems and values merge, thereby making it imperative to consider their national cultures and the cultural influence of interacting 
countries (Fagenson-Eland et al., 2004). Perlaki (1994) found that large power distances and strict hierarchical structures, with highly centralised decision-making, used to characterise societies and organisations in pre-revolutionary Eastern Europe. However, because of the transition to democracy, decision-making in these societies became less centralised. Organisations became less hierarchically structured and flatter with fewer levels of management. This influenced the selection of OD interventions and improved the possibility that they would adopt group process interventions.

Uncertainty avoidance as a dimension that differentiates national cultures: Uncertainty avoidance refers to the extent to which members of organisations do not tolerate unpredictability and ambiguity or accept uncertainty and risk (Hofstede, 1980). People in high uncertainty avoidance cultures respect figures of authority to ensure stability, tend to resist change, avoid conflict and taking risks and abide by many formal rules and regulations (Hofstede, 1980). In addition, in attempts to achieve certainty and avoid ambiguity, they are more likely to use strategic planning interventions, emphasise rules, tangible outcomes and highly formalised conceptions of management and to focus on hierarchical controls and task orientations (FagensonEland et al., 2004). According to Perlaki (1994), during the pre-revolutionary era when situations were ambiguous, those who held power in Eastern Europe countries tried to avoid uncertainty by standardising and formalising activities so that they created highly bureaucratic organisations that functioned using an array of rigid and detailed rules as well as regulations.

Specific interventions linked to the uncertainty avoidance dimension: To people in low uncertainty avoidance cultures, ambiguity is less threatening and they tend to make fewer rules, take more risks, engage more in participative decisionmaking and favour organic structures (Cummings \& Worley, 2001). Fagenson-Eland et al. (2004) found that Finland is high in uncertainty avoidance compared to New Zealand, South Africa, the UK and the USA. Therefore, its organisations are less likely to use culture change interventions. Finnish OD practitioners reflected the same degree of willingness to use culture change interventions as their counterparts in Ireland and the Netherlands did (Fagenson-Eland et al., 2004). However, they found that OD practitioners in Finland were not more likely to use management-style improvement interventions or strategic planning interventions than were any of the other countries, with the exception of the Netherlands.

Evidently, the kinds of interventions that organisations adopted related significantly to the countries' measures of uncertainty avoidance. Undoubtedly, the level of maturity of the OD practices in them could influence these interventions (Fagenson-Eland et al., 2004). In addition, Lau (1995) responded to the large number of misconceptions about the nature and usefulness of OD amongst Hong Kong managers and suggested that the concept of OD had not yet matured in Hong Kong.
Individualism vs. collectivism as a dimension that differentiates national cultures: Individualism is the degree to which people believe that they are responsible for themselves rather than to collectives like organisations or societies (Hofstede, 1980). Cultures that are high in individualism promote personal initiative, competitiveness, achievement and individual decision-making, whilst those lower in individualism (like Taiwan, Japan and Peru) emphasise allegiance to groups (Hofstede, 1996). According to Cummings and Worley (2001), organisations in individualistic cultures (like the USA and Canada) often have high levels of turnover and individual rather than group decision-making processes.

Individualistic cultures assume that employees' performance will improve if they receive direct feedback. However, in collectivist countries, this direct feedback destroys the harmony that governs and nurtures interpersonal relationships (Hofstede, 1996). With cultural differences, especially between eastern and western societies, it may be difficult to implement change processes that encourage openness between employees when they do not view them favourably. For example, Asian countries tend to be hierarchical and North American countries tend to be individualistic (M \& S, 2005).

Specific interventions linked to the individualism vs. collectivism dimension: Fagenson-Eland et al. (2004) found that all of the countries he studied (Finland, Ireland, the Netherlands, New Zealand, South Africa, the UK and the USA) were relatively high on individualism. Therefore, one would expect them to show no significant differences in using interventions that link to performance appraisal and rewards systems. However, Fagenson-Eland et al. (2004) found that the Netherlands used performance appraisal and rewards systems interventions significantly less than did their counterparts (in Ireland, New Zealand, Finland, the UK, South Africa and the USA). The implication is that developmental feedback is less necessary in demographically homogenous societies that define the roles and expectations of people in distinct social classes and work positions very well. In these environments, informal systems of feedback and well-defined social sanctions and norms play roles that are more significant (Fagenson-Eland et al., 2004). However, South Africa used these types of interventions significantly less often than did New Zealand, Finland and the USA.

Perlaki (1994) found that collectivist cultures characterised organisations and whole societies in Eastern Europe during the pre-revolutionary phase. He added that the transition resulted in more individualist organisational and societal cultures that resulted in the introduction of wage and salary differentiation between hardworking, productive employees and inefficient, incompetent ones, which were undifferentiated in the pre-revolutionary period. Therefore, the degree of individualism or collectivism determines the extent of openness and feedback and the choice and effectiveness of the OD interventions that organisations adopt. 
Masculinity vs. femininity as a dimension that differentiates national cultures: Masculinity is the degree to which members of organisations value traditionally male values like assertiveness, competitiveness and accumulating power and wealth (Hofstede, 1980). Organisations orientated towards femininity (like Sweden) emphasise personal relationships and a concern for others, or the female values of caring, compassion and submissiveness, more (DuBrin, 1997; Hofstede, 1996). Organisations in highly masculine cultures value career advancement and salary growth and tend to have high levels of stress and conflict. Organisations in feminine cultures tend to value the social aspects of work and have lower levels of stress and conflict (Hofstede, 1998; Cummings \& Worley, 2001). In addition, countries with high scores on masculinity value challenge, recognition and accomplishment (Bridges, 1997); continuous learning (Noe, 1999); think that work plays a pivotal role in one's life (Harzing \& Hofstede, 1996); and use technology more.

Perlaki (1994), who undertook a study of OD in Eastern Europe, found that, in the pre-revolutionary era, corporate and national cultures in Czechoslovakia, East Germany, Hungary and Poland were more feminine than were cultures in countries in the southern part of Eastern Europe (the former Yugoslavia, Bulgaria and Rumania), which have more differentiated social gender roles. However, the transition certainly led to more feminine and modern cultures in all countries in Eastern Europe.

Specific interventions linked to the masculinity vs. femininity dimension: Fagenson-Eland et al. (2004) found that Finland and the Netherlands have low scores on masculinity compared to Ireland, New Zealand, South Africa, the UK and the USA. Since OD interventions must be congruent with contextual values, one would expect that Finland and the Netherlands would be less likely to use OD interventions like training and development, career development, team building and technology integration (Fagenson-Eland et al., 2004). Whilst this expectation was true for training and development, only the Netherlands, and not Finland, used career-planning interventions for career development less often than did the other countries. With regard to team building, the USA and the UK were significantly more likely to use team building than did their counterparts in the Netherlands and Finland (FagensonEland et al., 2004).

In addition, OD practitioners in New Zealand and the USA were more likely to use technology integration interventions than were those in Finland. OD practitioners in New Zealand were also more likely to use technology integration interventions than were their counterparts in the Netherlands (Fagenson-Eland et al., 2004). Research by Fagenson-Eland et al. (2004) showed that the main types of OD change philosophies in the USA included technostructural and human process ones. In the UK, OD interventions focused on creating more humanistic environments through team building and motivational programmes. One may attribute these results to the USA being a world leader in technological interventions and integration in the business environment. Although the UK and South Africa use technology substantially, traditions may bind them more than it does in the USA (Fagenson-Eland et al., 2004). Evidently, the kinds of OD interventions that organisations apply align with the values of countries and their beliefs.

\section{Inter-relationships between the power distance, uncertainty avoidance, individualism vs. collectivism and the masculinity vs. femininity dimensions}

Hofstede (1980) compared the beliefs and values of employees in the subsidiaries of a large multinational corporation in 40 countries around the world and assessed interrelationships between the four dimensions of national cultures. Hofstede's findings follow.

There is no relationship between small power distance and collectivism. However, there is a tendency for large power distance to be associated with collectivism and small power distance with individualism. A third intervening variable is national wealth. Small power distance and individualism both link to greater national wealth, thereby indicating that poorer countries show collectivism whilst wealthier countries are individualistic. Present-day Austrian culture shows high uncertainly avoidance with very low power distance compared to Japan and Mediterranean countries, which combine high uncertainty avoidance with high power distance. This means that a powerful boss can receive both praise and blame as a strategy to avoid uncertainty. However, Austrian culture, like the German, Swiss, Israeli and Finnish cultures, cannot depend on external superiors to circumvent its uncertainty. According to Hofstede (1980), in strong uncertainty avoidance countries like Austria, inner urges and feelings of obligation to society lead to hard work.

Whilst power distance has a relationship with centralisation, uncertainly avoidance links to formalisation or the need for formal rules and specialisation. The extremely high level of individualism in the USA leads to a need to explain every act in terms of self-interest. The high position of the USA on the individualism scale leads to other potential conflicts between its way of thinking about organisations and the values that dominate in other parts of the world. In the individualistic rationale of the USA, the link between people and their organisations is calculative and based on self-interest. However, in collectivist societies, the links are not calculative but moral. Their basis is not self-interest but people's loyalty to their clans, organisations or societies.

The combination in the USA of weak uncertainty avoidance and relatively high masculinity justifies the Americans' high level of achievement motivation. The USA and Scandinavian cultures differ largely on the masculinity dimension. Using intuition and concerns about participation and consensus in Scandinavian cultures reflect femininity, whilst facts and clear responsibilities illustrate the masculine USA culture. These differences in cultural values influence the selection of 
OD interventions. Because of globalisation, multicultural and multinational organisations will demand that OD consultants note these cultural differences and intervene in contexts with suitable combinations of tailor-made interventions that are congruent with local contexts and beliefs if they are to be effective.

\section{DuBrin's identification of differences in cultural values that influence the selection of organisational development interventions}

DuBrin (1997) identifies further differences in cultural values that influence the selection of OD interventions.

Long-term orientation vs. short-term orientation: Workers from cultures with long-term orientations (like the Pacific Rim countries) maintain long-range perspectives. They practise perseverance, thrift (Hofstede, 1996) and do not demand quick returns on their investments. However, employees from cultures with short-term orientations (in countries like the USA and Canada) demand immediate results and tend not to save (DuBrin, 1997). They respect traditions, reciprocate gifts and give favours more (Wikipedia, OC, 2006).

Formality vs. Informality: Countries, which value formality, attach tremendous importance to traditions, ceremonies, social rules and rank (like the Asian and Latin American countries). Perlaki (1994) found that the incongruence and major misfits between pre-revolutionary eastern European cultures and OD values were not the only obstacles to successful OD interventions. A serious weakness was their rigid, bureaucratic and formalised planning methodology. The converse is true of countries that value informality (like the USA, Canada and Scandinavian countries [see DuBrin, 1997 and Hofstede, 1996]).

Urgent time orientation vs. casual time orientation: Nations and people differ in the value they attach to time. People with urgent time orientations (like Americans) see time as a scarce resource, impose deadlines and tend to be impatient. Those with casual time orientations (like China) see time as an unlimited and unending resource and tend to be patient (DuBrin, 1997; Meyer, 2002). However, Chinese people complete large-scale projects quickly despite their casual time orientation because of the emphasis they place on personal relationships.

High-context vs. low-context cultures: Cultures differ in the degree of importance they attach to circumstances, contexts or events. High-context cultures (like the Asian and AfricanAmerican ones) use body language more extensively. The converse is true of low-context cultures (like the northern European ones). They are more likely not to use their time for business dealings but build relationships and establish trust instead (DuBrin, 1997).

\section{Trompenaars' seven dimensions of culture}

Trompenaars (Advanced Workplace Associates, 2002) identified seven dimensions of culture that one must consider when working in multicultural contexts and when dealing with change. They are universal vs. particular solutions, individualism vs. community, neutral vs. emotional, specific vs. diffuse, achievement vs. attribution and attitudes to time vs. attitudes to the environment. These factors, according to Trompenaars, surface in the attitudes of different nationalities to change and in their acceptance of global solutions to problems. Nationalities, like the UK and the USA, tend to prefer to adopt universal solutions because they regard people as more important than communities. They are neutral in their responses and prefer specific solutions rather than to establish wider relationships (Advanced Workplace Associates, 2002). In the UK and the USA, people receive rewards for achievements. These countries value development potential relative to achievements. Attitudes to the environment are less critical. The Germans, Swedes, Dutch and Swiss have strong preferences for rules and value universal solutions. The French and Italians do so to a lesser extent. South American countries, China and eastern European cultures prefer to address problems in their own contexts. Universalist cultures view this behaviour as corrupt whilst particularist cultures perceive the strict rules as being unfeeling and cold (Advanced Workplace Associates, 2002).

Whilst Americans would promote individual responsibility and accountability, the French and Japanese would prefer management teams that have collective responsibilities. Therefore, the French may regard the Americans as being naïve, addicted to work, aggressive and unprincipled whilst Americans may regard the French as arrogant, flamboyant, hierarchical and emotional (Advanced Workplace Associates, 2002). The implication is that failures in multicultural partnerships and alliances are largely the result of this stereotyping, misreading and misjudging of behaviour through varying sets of cultural norms. This results in critical decisions based on mistaken perceptions (Advanced Workplace Associates, 2002). What one needs are investments in relationships with partners. Although time consuming, they can result in stronger and longer lasting alliances with sustained performance improvements.

\section{Contextual differences in management practices and their effect on organisational development interventions}

Hofstede (1998) and Hoppe (2004) emphasise the influence of national cultures on management practices and organisations. Leaders and managers have norms that determine standards of appropriate behaviour, which they use to resolve conflict. These norms have cultural foundations and explain differences in conflict management outcomes. Hofstede (1993) found that the American type of manager does not exist in Germany, Japan, France or Holland. German managers focus on productive roles rather than on leadership ones, Japanese managers see permanent worker groups as the core of enterprises, French managers focus on cadres vs. non-cadres and the honour of their class, and Dutch managers concentrate on the need for consensus between all parties using open exchanges of views. In the USA, the core of enterprises is the management class (Hofstede, 1993). 
Tinsley \& Brett (2001) conducted a study on American and Hong Kong Chinese managers and found that the American managers exhibited the traditional American norms of discussing parties' interests and synthesising several issues more strongly than their Hong Kong Chinese counterparts did. Furthermore, they reported that the traditional Chinese norms of concern for collective interest and concern for authority appeared more strongly in Hong Kong Chinese managers than they did in their American counterparts. American managers were more likely than their Hong Kong Chinese counterparts were to resolve a greater number of issues and reach more integrative outcomes, whilst the latter were more likely to involve senior managers when resolving conflicts. They concluded that cultures had a significant influence on whether parties selected an integrative outcome rather than one that involved distribution, compromise, senior managers - or found no resolution at all. In addition, Kozan (1993) noted the influence of cultures on participative management techniques and individual initiative. Therefore, cultures influence how and where OD consultants intervene and what they focus on.

\section{Discussion}

\section{Critical success factors for organisational development practitioners who work in multicultural contexts}

Many planned OD interventions do not achieve their goals they fail to change the cultures of organisations because the national cultures in which organisations are embedded, and from which they draw their people, affect them. The third and deepest level of Schein's (1985) organisation model reflects the possibility of paradoxical organisational behaviours. What seems apparent at the first level may be completely different at the third level. Whilst one may notice some behavioural changes, there may not be real attitudinal changes (Harvey, 2006). Evidently, culture change is not an easy process because cultures are rooted in the collective histories of organisations and because large proportions of them are below the surface of awareness. Many OD consultants fail to realise their goals because very often they do not grasp the unspoken cultural norms before the change agents begin their actions. However, just understanding cultures at the deepest level may not be sufficient to implement cultural change because the intricacies of interpersonal relationships slot into the intricacies of organisational culture in the process of implementing desired changes (Wikipedia, OC, 2006).

The implication is that OD culture consultants need to take careful cognisance of the existence of paradoxical organisational behaviours and the dynamics of interpersonal relationships in the threatening conditions of an OD culture change process. Clearly, the success of interventions will depend on complete diagnostic information and evaluation of contexts whilst taking advantage of Pan European and global knowledge. This means being able to draw on the expertise of all the nations of Europe, collectively or in collaboration with one another, and admitting that OD consultants could become multinational integrated service providers.
It is certainly necessary for OD consultants to evaluate the relationship between OD and national values. Jaeger (1986) analysed the relationship between them. He found that the three Scandinavian countries (Denmark, Norway and Sweden) came closest to alignment with OD values. Even the values of the USA, which practises OD widely and accepts it, were not entirely congruent with OD values. Most Asian and Latin American countries (including Hong Kong) had poorer alignment with core OD values.

However, the congruence of national cultural values and OD values will help consultants to select the OD interventions they should use in given countries. It is clear that OD interventions will be effective when practitioners believe in OD values. This means involving people in decisions that directly affect them, confronting and managing the constant incongruency between individual needs and the goals of groups and organisations, and acknowledging the right of employees to open and honest information, communication and feedback (French \& Bell, 1999). The essence is to ensure that practitioners understand the principles of OD and that their interventions are congruent with the visions and values of organisations. This will enable them to define the required culture change in organisations and move them towards visions that are consistent with their values. Figure 2 gives a selection of intervention techniques that suit the specific type of national cultures that Hofstede (1980) differentiated. However, it is important to note the evolving nature of the political and economic climates that influence national cultures, thereby emphasising the need for interventions that reflect OD values, are tailor-made and shaped to the needs of local cultures.

Companies can no longer ignore the intense competition from organisations half a globe away that can often produce better quality at cheaper prices. For example, organisations in the USA are increasingly aware of the immense potential of markets that are emerging in Eastern Europe, China and Latin America because 'to ignore such possibilities is to be left behind, to be trampled in the dust of more assertive and globally aware competitors' (Eisen, 1995, p. 1). Some responses to this situation may be to think globally and act locally (Shephard in Eisen, 1995). However, Eisen (1995) believes that we often find ourselves 'acting globally by acting locally'.

Therefore, OD consultants who operate in a global society and in trans-organisational domains need to note their clients' contextual systems and, together with their clients, search for appropriate OD interventions. This means noting social linguistic aspects, organisational structures, communication and interaction processes, cultures and belief systems as well as the technologies all people in the global society share (Eisen, 1995). OD consultants must be able to deal with complex, deep seated, challenging and paradoxical issues whilst working in the dynamic intricacies of systems, structures and interpersonal relations that are embedded in certain contexts. 


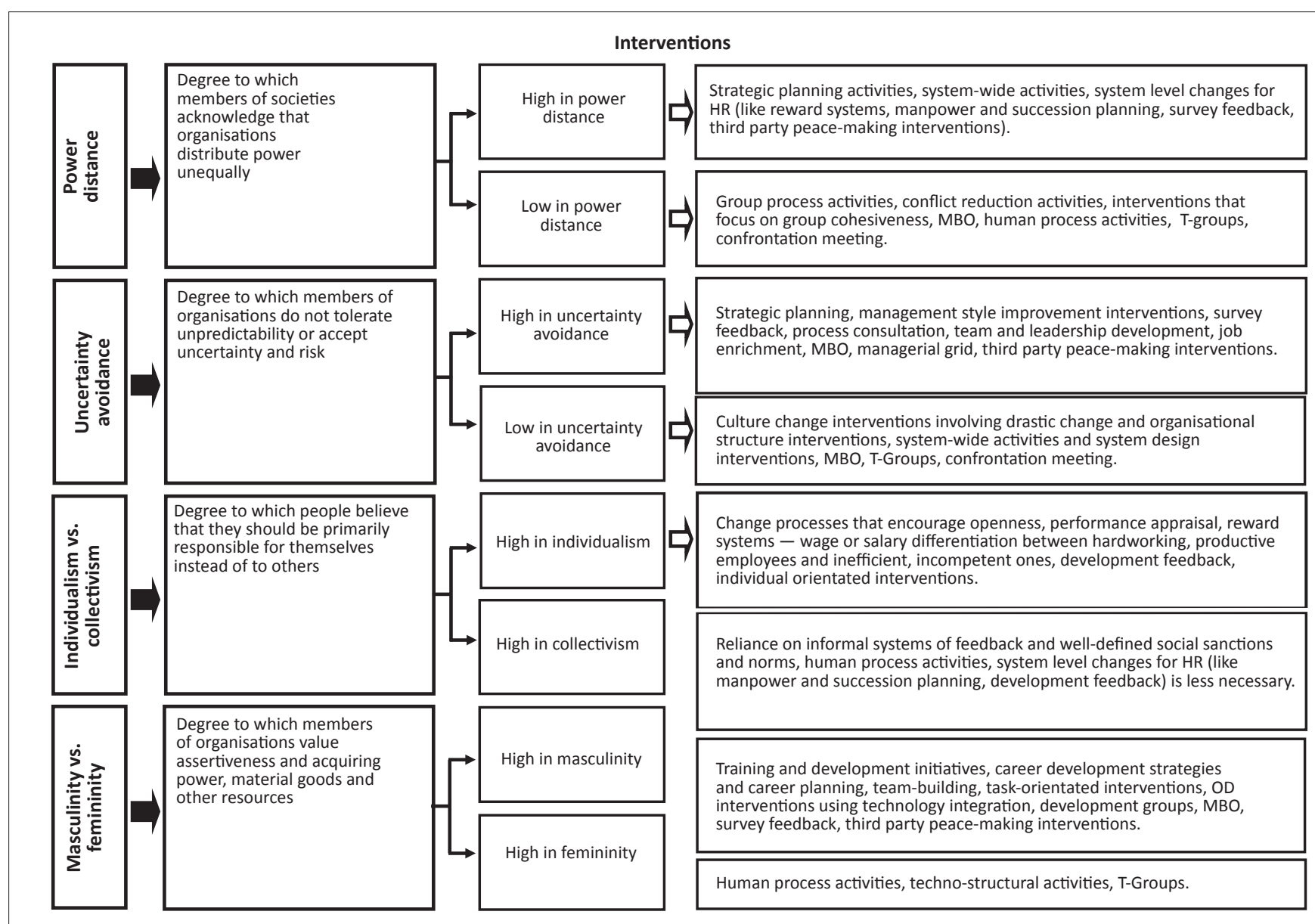

$\mathrm{HR}$, human resources; $\mathrm{MBO}$, management by objectives; T-groups are training-groups or therapy-groups.

FIGURE 2: Interventions that link to Hofstede's dimensions for differentiating national cultures.

\section{Conclusions}

Practitioners need systematic and congruent organisational structures, systems, strategies and designs if they are to implement OD interventions successfully. In addition, they need to note the dynamic nature of organisations, which numerous internal and external factors constantly influence, and create the need for organisations to change and adjust to their environmental pressures and opportunities. Because of global competition, technological advancements and economic changes, practitioners have created a variety of OD interventions that aim to redesign organisations, change their cultures and align corporate strategies to external demands and opportunities. These changes have expanded the robust and growing field of OD. They have also had significant implications for OD practitioners or consultants. They emphasise that it is necessary to align the practices and techniques of OD so that they can adapt to the values and cultures of organisations and societies where they are to be implemented. The varying values and unique dimensions of cultures, which the various countries and societies espouse, emphasise that it is necessary to achieve congruence between OD and national values and for organisations to believe in, and support, OD values.

\section{References}

Advanced Workplace Associates. (2002). True Global Partnering: Advanced Working Papers - A series of thought provoking insights into work and the workplace Retrieved August 20, 2006, from http://www.occupier.org/uploads/articles/ Retrieved Augu

Bennis, W. (2002). Effective Leadership has never been in greater demand. Retrieved August 20, 2006, from www.PeopleSoft.com/think-tank

Blair, M., Sorensen, P., \& Yaeger, T. (2002). OD Practitioner. Journal of the Organization Development Network, 34(1), http://www.odnetwork.org/odponline/vol34n1/ fromtheeditors.html

Boonstra, J., \& Vink, M. (1996). Technological and Organisational Innovation: a dilemma of fundamental change and participation. The European Journal of Work and Organisational Psychology, 5(3), 54-58. http://dx.doi. Journal of Work and Organisationa
org/10.1080/13594329608414865

Bridges, W. (1997). Creating You and Co. Reading, MA: Addison-Wesley.

Brooks, I., \& Bate, P. (1994). The Problem of Effecting Change Within the British Civil Service: a cultural perspective. British Journal of Management, 5, 177-190. http://dx.doi.org/10.1111/j.1467-8551.1994.tb00169.x

Cummings, T.G., \& Worley, C.G. (2001). Essentials of Organization Development and Change. Australia: South-Western College Publishing.

Deal, T.E., \& Kennedy, A.A. (1982). Corporate Cultures: The Rites and Rituals of Corporate Life. Harmomdsworth: Penguin Books.

DuBrin, A.J. (1997). Fundamentals of Organizational Behavior: An Applied Approach. Cincinnati, Ohio: South-Western College Publishing.

Eisen, S. (1995). Redesigning Human and Global Systems: A Conceptual and Strategic Framework. Presented at the Academy of Management and Case-Western Reserve University Joint Divisional Conference on the Organizational Dimensions of Global Change. Cleveland, Ohio.

Evans, P. (1989). Organization development in the transnational enterprise. In R. Woodman \& W. Pasmore (Eds.), Research in organizational change and development, Volume 3 (pp. 1-38), London: JAI. 
Fagenson-Eland, E., Ensher, E.A., \& Burke, W.W. (2004). Organization Development and Change Interventions. The Journal of Applied Behavioral Science, 40(4), 432464. http://dx.doi.org/10.1177/0021886304270822

French, W.L., \& Bell, C.H. (1999). Organization Development: Behavioral Science Interventions for Organization Improvement. (6th edn.). New Jersey, Saddle River: Prentice-Hall.

Glassman, A.M., \& Cummings, T.G. (1991). Cases in Organizational Development Boston: IRWIN, Homewood, IL.

Golembiewski, R.T. (1993). Organizational development in the third world: Values, closeness of fit and culture-boundedness. International Journal of Public Administration, 16(11), 1667-1691. http://dx.doi. org/10.1080/01900699308524866

Golembiewski, R.T., \& Luo, C. (1994). OD applications in developmental settings: An addendum about success rates. The International Journal of Organizational Analysis, 2(3), 295-308. http://dx.doi.org/10.1108/eb028814

Hamlin, R.G. (2005). Towards universalistic models of managerial leader effectiveness: a comparative study of recent British and American derived models of leadership. Human Resource Development International, 8(11), 5-25. http://dx.doi. org/10.1080/1367886042000338254

Hamlin, B., Campbell, F., Reidy, M., \& Stewart, J. (1999). In support of researchbased organisation change and development through professional partnerships. based organisation change and development through professional partnerships.
Occasional Paper Series, Number OP002/99. ISSN 1464-1747. Wolverhampton Business School: Management Research Centre, 1-23.

Hamlin, R.G., Keep, J., \& Ash, K. (2001). Organisational change and development: a reflective guide for managers, trainers and developers. Harlow: Financial Times, Prentice Hall.

Handy, C.B. (1985). Understanding Organizations. (3rd edn.). Marmondsworth: Penguin Books.

Harrison, A.P., Wheeler, P., \& Whitehead, C. (2003). The Distributed Workplace. London: Taylor \& Francis Group, Spon Press.

Harvey, R. (2006). Organisational Development and Emotional Intelligence. Retrieved August 20, 2006, from http://www.emotionalintelligence.co.uk/ezine/ dowloads/01_Feature.pdf

Harzing, A., \& Hofstede, G. (1996). Planned change in organizations: The influence of national culture. Research in the Sociology of Organizations, 14, 297-342.

Head, T., \& Sorensen, P. (1993). Cultural values and organization development: A seven nation study. Leadership and Organization Development Journal, 14, 3-7. heven nation study. Leadership and Organization

Hofstede, G. (1980). Motivation, leadership and organization: Do American theories apply abroad? Organizational Dynamics, 9(1), 42-63. http://dx.doi. org/10.1016/0090-2616(80)90013-3

Hofstede, G. (1993). Cultural constraints in management theories. Academy of Management Executive, 7(1), 81-94.

Hofstede, G. (1996). The cultural relativity of organizational practices and theories. In J. Billsberry (Ed.), The effective manager: Perspectives and illustrations (pp 243-262). Thousand Oaks, CA: Sage.

Hofstede, G. (1998). A case for comparing apples with oranges: International differences in values. International Journal of Comparative Sociology, 39, 16-31. http://dx.doi.org/10.1177/002071529803900103

Hoppe, G. (2004). An interview with Geert Hofstede. Academy of Management Executive, 18, 75-79. http://dx.doi.org/10.5465/AME.2004.12689650

Howard, J.H. (2006). External Pressure for Change. Knowledge Intensive Services Activities Conference. Services Innovation. University of Western Sydney and Howard Partners Pty, Ltd.

Institute of Personnel and Development. (2005). Workplace Learning, Culture and Performance. Chapter 4. Retrieved August 20, 2006, from http://www.logos-net. net/ilo/195 base/en/publ/019.html

IRS. (1997). Cultural Change. IRS Management Review, 11(4), 13-15.

Jaeger, A. (1986). Organization Development and National Culture: Where's the Fit? Academy of Management Journal, 11, 178-190. http://dx.doi. org/10.2307/258339

Johnson, G. (1988). Rethinking Incrementalism. Strategic Management Journal, 9 75-91. http://dx.doi.org/10.1002/smj.4250090107

$\begin{gathered}\text { Kane-Urrabazo, } \\ \text { organizational }\end{gathered}$
C. (2006). Management's role in shaping 188-197. $\quad \mathrm{http}: / / \mathrm{dx}$.doi.org/10.1111/j.1365-2934.2006.00590.x; PMid:16600006

Kim, N., \& Hoon, S. (1998). The concept and dynamics of peace: Implications for organizational behavior in Asia. Organization Science, 9, 522-534. http://dx.doi. org/10.1287/orsc.9.4.522

Kirkbride, PS., Tang, S.F.Y., \& Shae, W.C. (1989). The transferability of management training and development: the case of Hong Kong. Asia Pacific Human Resource Management, 27(1), 7-19. http://dx.doi.org/10.1177/103841118902700103

Kotter, J. (1996). Leading Change: why transformation efforts fail, In J. Champy \& N. Nohria (Eds.). Fast Forward: the best ideas on managing business change. Boston, M.A.: Harvard Business Press.

Kozan, M.K. (1993). Cultural and industrialization level influences on leadership attitudes for Turkish managers. International Studies of Management and Organization, 23, 7-17.
Lachman, R., Nedd, A., \& Hinings, B. (1997). Analyzing cross-national management and organizations: A theoretical framework. In H.V. Wortzel \& L.H. Wortzel (Eds.), Strategic Management in a Global Economy (pp. 503-521). New York: John Wily \& Sons, Inc.

Lau, C., \& Ngo, H. (2001). Organization development and firm performance: A comparison of multinational and local firms. Journal of International Business Studies, 32, 95-114. http://dx.doi.org/10.1057/palgrave.jibs.8490940

Lau, C.M. (1995). Organization development practices in Hong Kong: current state and future challenges. Asia Pacific Journal of Management, 12(1), 101-114. http:// dx.doi.org/10.1007/BF01733974

Lau, C., McMahan, G.C., \& Woodman, R.W. (2005). An international comparison of organization development practices: The USA and Hong Kong. Retrieved August 20, 2006, from http://www.emeraldinsight.com/Insight/html/Output/Published/ EmeraldFull TextArticle/Articles/02300902

M \& S. (2005). Change Management at Marks and Spencer. Retrieved August 20, 2006, from http://www.sagepub.co.uk/millward/files/slides/Chapter5_notes.doc

McElroy, J.L., \& Morris, L. (2002). African Island Development Experiences: A Cluster of Models. Indiana, USA: Indiana Association of Social Sciences Meeting.

Meyer, M. (2002). Managing Human Resource Devleopment: An outcomes-based approach. (2nd edn.). Durban: LexisNexis Butterworths.

Mutabazi, E., \& Derr, C.B. (2006). The Management of Multicultural Teams: The Experience of Afro-Occidental Teams. Numero, 2003/13. Retrieved August 20, 2006, from http://www.em-yon. com/WorkingPapers/2003-13.pdf

Nilakant, V., \& Ramnarayan, S. (2006). Change Management: Altering Mindsets in a global context. New Delhi: Sage Publications, Response Books.

Noe, R. (1999). Introduction to employee training and development. In R. Noe (Ed.), Employee training and development. New York: McGraw-Hill.

Observatory of Cultural Policies in Africa and Interarts Workshop on Draft Projects Documents on the Research Priorities and Consultation on the Report on Cultural Diversity in Africa. (2006). Workshop of Experts on the Search of Indicators and the African Contribution to the UNESCO World Report on Cultural Diversity. Maputo, 15-17 February, 2006. Retrieved August 20, 2006, from http://ocpa.irma.hr/ activities/meetings/maputo2006/Workshop_Final_Report-en.pdf

Ogbonna, E., \& Harris, L.C. (2002). Managing organisational culture: Insights from the hospitality industry. Human Resource Management Journal, 12(1), 33. http:// dx.doi.org/10.1111/j.1748-8583.2002.tb00056.x

Parnell, J.A., Crandall, W.R., \& Menefee, M. (2005). Examining the impact of culture on entrepreneurial propensity: An empirical study of prospective American and Egyptian Entrepreneurs. Retrieved August 20, 2006, from http://www. alliedacademies.org/archive/aij/aej1-1/paper4.html

Perlaki, I. (1994). Organizational Development in Eastern Europe: Learning to Build Culture-Specific OD Theories. Journal of Applied Behavioural Science, 30(3), 297312. http://dx.doi.org/10.1177/0021886394303003

Peterson, L.A. (1997). International HRD: What we know and don't know. Human Resource Development Quarterly, 81, 63-79.

Pettigrew, A., Woodman, R., \& Cameron, K. (2001). Studying organizational change and development: Challenges for future research. Academy of Management Journal, 44, 697-713.

Red Barnet. (2001). Ethiopia: Socioeconomic Analysis. Retrieved August 20, 2006 from http://222redbarnet.dk/Files/Filer/om_RB/Programpresentation/2001/ treEtiopian.doc

Response to the Commission's Consultation Document. (2004). Action for a strong and prosperous Africa: the response. December 2004. Retrieved August 20, 2006, from http://www.commissionforafrica.org/english/consultation/online/ onlineforums/sebsite debate/Com_Web_Deb_Fin-Rep_en.pdf

Russell, R.D. (1997). The Impact of National Culture on the Emergence of Entrepreneurship.

Schein, E.H. (1985). Organizational Culture and Leadership. (3rd edn.). Jossey-Bass.

Thomas, A., \& Bendixen, M. (2000). The management implications of ethnicity in South Africa. Journal of International Business, 31, 507-519. http://dx.doi. org/10.1057/palgrave.jibs.8490919

Tinsley, C.H., \& Brett, J.M. (2001). Managing Workplace Conflict in the United States and Hong Kong. Organizational Behaviour and Human Decision Processes, 85(2), 360-381. http://dx.doi.org/10.1006/obhd.2000.2944 PMid:11461206

Warrick, D. (1995). Best practices occur when leaders lead, champion change and adopt a sound change process. Organisation Development Journal, 13(4), 91-102.

Westwood, R.I., Tang, S.F.Y., \& Kirkbride, P.S. (1992). Chinese conflict behavior: cultural antecedents and behavioral consequences. Organization development Journal, 10(2), 13-19.

Wikipedia, OC. (2006). Organisational Culture. Retrieved August 20, 2006, from http://en.wikipedia.org/wiki/Organizational_culure

Wikipedia, OD. (2006). Organisational Development. Retrieved August 20, 2006, from http://en.wikipedia.org/wiki/Organizational_development

Worley, C.G., \& Feyerherm, A.E. (2003). Reflections on the Future of Organization Development. The Journal of Applied Behavioral Science, 39(1), 97-115. http:// dx.doi.org/10.1177/0021886303039001005

Zondo, M.A.R. (2001). Quality Leadership: Challenges, Strategies and the Zimbabwean Experience. International Review of Administrative Sciences, 67, 237. http:// dx.doi.org/10.1177/0020852301672004 